island in the West Indies, and family planning clinics have been set up by a voluntary organization and have been widely used. The discussion provoked by this paper lasted throughout the lunch hour.

In the afternoon Dr. Henry reported on the survey of diabetes in Trinidad. Of a random sample of more than 24,000 people, representative of the whole population of the Island, there was a 98 per cent response-rate. The total incidence of diabetes was found to be 1.88 per cent. Dr. Quamina demonstrated that the age of sexual maturation of Trinidadian schoolgirls was not earlier than that of girls in temperate climates. Dr. Miall described the surprisingly high incidence of angina found in a Jamaican rural population; this condition is associated with hypertension, high serum globulin-levels and abnormal hremoglobins. Dr. Milner reporte, ${ }^{3}$ a family with hæmoglobin D which was found in the course of the aforementioned survey. Another rarity was described by
Dr. McDowall of Trinidad, who reported a syndrome resembling rickets, but associated with hypercalcæmia, which only affected the girls of a large Indian family.

The meeting was attended not only by numerous medical workers from the Caribbean area but also by representatives of the Pan-American Health Organization (World Health Organization), the National Institutes of Health, Harvard University, the Communicable Diseases Center, Georgia, and the Massachusetts Institute of Technology in the United States, and the Department of Technical Co-operation, the Tropical Medicine Research Board and the Medical Research Council of Great Britain.

The meeting indicated that medical research under the auspices of the Standing Advisory Committee is in a healthy and developing state and further important scientific contributions from the area concerned can be confidently expected.
J. S. GarRow

\title{
METEOROLOGICAL SATELLITES AND THE WORLD WEATHER WATCH
}

$\mathrm{T}$ $\mathrm{HE}$ fourth Congress of the World Meteorological Organization was held at Geneva during April, and among the major questions discussed were plans for future meteorological satellites and further steps towards a World Weather Watch. The Congress was informed of the agreements between Soviet and American authorities regarding their satellite programmes.

Weather satellites will not, of course, replace the present world-wide network of meteorological stations, but will, as one of their main tasks, fill in the 'blanks' in the weather charts over oceans, deserts and polar regions. The United States will launch several more Tiros satellites in 1963 and 1964 at approximately four-monthly intervals to ensure the continued availability of satellite picture data until their more advanced Nimbus satellite can be proved operationally successful. Various orbits will be tested and also equipment, including instruments for further measurements of infra-red radiation. It is hoped to test an automatic picture transmission system intended for use on Nimbus. The automatic picture transmission system is a remarkable new development designed to take and transmit pictures for reception by a relatively inexpensive receiving station. The Congress was cautioned, however, that the whole satellite programme is still in an experimental stage and further experience might lead to modifications in the apparatus.

The Nimbus meteorological satellite will be developed between 1963 and 1966 and will furnish higher quality data than the Tiros programme and in greater quantity. It will be Earth orientated so that one of its three cameras. pointing straight downwards, will view the Earth's atmosphere or surface directly below the space-craft, thus simplifying the problem of adjusting cloud pictures to fit a map. The orbit will be nearly polar to allow almost total daily coverage of the Earth-every part of the Earth (except where there is polar darkness) will be seen in sunlight at least once every $24 \mathrm{~h}$, and the same area can be seen day after day (whereas the Tiros satellite can see a given area for limited periods only). Electronic computers will be used to convert data into forms suitable for daily weather analysis and forecasting; for example, geographic grids (latitude and longitude) will be produced to superimpose on the pictures, and maps showing cloud cover and type will be made to help to interpret the picture data.

The solution of the problem of the general circulation of the atmosphere would assist the rapidly growing applications of meteorology to economic activities. Before progress can be made with this problem certain gaps must be filled in the existing network of observations, and adequate supporting communications systems established. The Congress decided on a comprehensive plan for a World Weather Watch which would include improvement of the present network, the organization of upperair measurements from merchant ships, and the exploration of the possibilities of automatic weather stations, of weather satellites and of co-operation with oceanographic interests. The rapidity of scientific and technical develop. ments has led the Congress to call for the establishment of an advisory committee of eminent scientists who will advise the Organization on research and operational problems, especially in the light of data obtainable from artificial satellites.
W. S. GARRIOCK

\section{STATISTICS OF EDUCATION IN BRITAIN}

$\mathrm{T}$ HE Minister of Education has recently published Part 1 of the Statistics of Education, 1962, in an attractive new format*. This comprises the bulk of the data dealing with schools: the remainder, which deal with examinations for the General Certificate of Education, further education, awards, teacher training, school health and educational building, will appear later.

The first section deals with births, population of school age, and projections of these figures to 1985 . The demographic part of the projection was undertaken by the

* Ministry of Education. Statistics of Education, 1962. Part 1. Pp. ii + 128. (London: H.M.S.O., 1963.) 20s. net.
Government Actuary and the General Register Office; in addition, it was assumed that the Christmas leaving date would be eliminated after 1963-64, and that the trend towards later leaving shown in the past nine years would continue up to 1985 . On these assumptions, the increase in the school population in 1985 over 1960 would be 28 per cent at ages $5-10,8$ per cent at ages $11-14$, and 159 per cont at ages 15 and over. The assumptions imply that by 1985,35 per cent of the 16-year-olds and 20 per cent of the 17 -year-olds will stay at school: the corresponding percentages in 1960 were 15 and 8 . The magnitude of the tasks before the educational system will be apparent from these figures. 